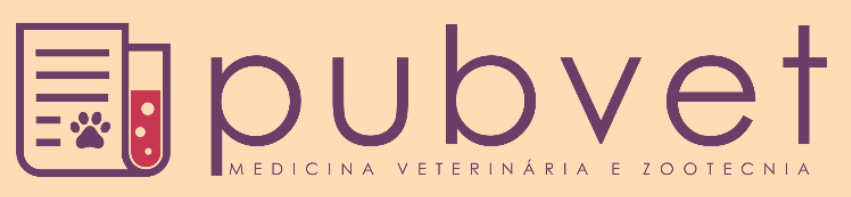

https://doi.org/10.31533/pubvet.v15n05a814.1-7

\title{
Taxa de prenhez e tamanho da ninhada de cadelas Buldogue Inglês inseminadas com sêmen fresco
}

\author{
Carla Fredrichsen Moya $^{1^{*} \bullet}$, Bruna Muniz Sanchez Hernandes ${ }^{2}$, Flávio Camargo Leme ${ }^{2}$, \\ Annelise Carla Camplesi ${ }^{30}$
}

${ }^{I}$ Docente da Universidade Estadual do Centro-Oeste, UNICENTRO, Departamento de Medicina Veterinária. Guarapuava - PR, Brasil. ${ }^{2}$ Médico(a) Veterinário(a), Clínica Veterinária Canguru. Ourinhos - SP, Brasil.

${ }^{3}$ Docente da Faculdade de Ciências Agrárias e Veterinárias, FCAV/UNESP, Departamento de Clínica e Cirurgia Veterinária. Jaboticabal - SP, Brasil. *Autora para correspondência, E-mail: carlafredrichsen@yahoo.com.br

Resumo. O presente estudo teve por objetivo a avaliação do ciclo estral por meio de citologia vaginal para a escolha do momento da inseminação artificial de cadelas da raça Bulldog com sêmen fresco, além da determinação da taxa de prenhez e o tamanho das ninhadas. Utilizaram-se 16 cadelas da raça Buldogue inglês, com histórico de boa fertilidade reprodutiva e idade variando de 1,5 a 6 anos. Associada a detecção do proestro realizou-se a citologia vaginal da fêmea para detecção do estro, bem como a observação do comportamento de aceitação do macho. As inseminações foram realizadas, quando a citologia vaginal apresentava pelo menos $90 \%$ de células superficiais, a cada 48 horas até mudança na citologia vaginal para diestro e/ou quando a fêmea deixava de aceitar o macho. Para a colheita do sêmen, empregou-se a manipulação digital, os reprodutores passaram por um exame andrológico prévio sendo selecionados os animais com uma motilidade mínima de $70 \%$, vigor 3 e pelo menos $200 \times 10^{6}$ de espermatozóides. A inseminação foi realizada pela técnica intravaginal empregando-se todo ejaculado. $\mathrm{O}$ diagnóstico de gestação foi realizado entre os dias 25 a 30 de gestação, por meio de exame ultrassonográfico, sendo posteriormente feitos periodicamente para a escolha do momento apropriado para a cesariana. $\mathrm{O}$ exame da citologia vaginal, associado às características anatômicas e comportamentais, foi eficiente para detectar o estro em $100 \%$ das fêmeas. Das 16 fêmeas inseminadas, $87,50 \%$ (14/16) ficaram prenhes. As ninhadas tiveram em média 5,6 filhotes, desses 53,16\% (42/79) eram machos e 46,84\% (37/79) fêmeas. A IA com sêmen fresco associada à citologia vaginal proporcionou bons resultados de fertilidade bem como ninhadas de tamanho compatível para a raça em questão.

Palavras chave: Biotecnologias reprodutivas, citologia vaginal, gestação, canino

\section{Pregnancy rate and litter size of English Bulldog bitches inseminated with fresh semen}

Abstract. The present study aimed to evaluate the estrus cycle of Bulldog bitches using
vaginal cytology, and to inseminate these with fresh semen, leading to the determination
of pregnancy rate and the size of the litter. Sixteen (16) English Bulldog breed bitches were
used, all with good reproductive history and proved fertility, age ranging from 1.5 to 6
years. Associated with the proestrus detection (external signs: vulva edema and a blood-
stained discharge) was performed the vaginal cytology in order to determine the estrus
moment, as well was observed the female behavior of male acceptance. The artificial
inseminations (AI) started when the vaginal cytology showed $90 \%$ of superficial cells, then
repeated every $48 \mathrm{~h}$ until the vaginal cytology change to diestrus (increasing the nucleated
cell counting) and/or the bitch stop to accept the dog mating. To perform the semen 
collection were used the digital manipulation, all male breeders undergo to a previous seminal examination being select for use only ejaculates with more than $70 \%$ of total motility, vigor 3 and, at least, $200 \times 10^{6}$ of spermatozoa. The AI was performed using all the collected ejaculate. The gestation confirmation was made by transabdominal ultrasonography between 25 and 30 days after the last AI, the ultrasonographic evaluation after that was carried out periodically in order to determine the best moment to execute the c-section. The vaginal cytology evaluation, associated with the compartmental changes in the bitch was efficient to detect the estrus onset in $100 \%$ of the bitches. Get pregnant 14 of the 16 bitches inseminated (87.5\%). The litters had a mean number of 5.6 puppies, of those $53.16 \%$ (42/79) were male and $46.84 \%$ (37/79) were female. The AI with fresh semen associated with vaginal cytology provided good fertility results and size of litters compatible in English Bulldog under these experimental conditions.

Key words: Reproductive biotechniques, vaginal cytology, gestation, canine

\section{Tasa de preñez y tamaño de la camada de perras Bulldog Inglés inseminadas con semen fresco}

Resumen. El presente estudio tuvo como objetivo evaluar el ciclo estral mediante citología vaginal para elegir el momento de inseminación artificial de hembras Bulldog con semen fresco, además de determinar la tasa de gestación y el tamaño de las camadas. Se utilizaron 16 hembras Bulldog Inglés, con un historial de buena fertilidad reproductiva y edades comprendidas entre 1,5 y 6 años. Asociado a la detección del proestro, se realizó la citología vaginal de la hembra para detectar el estro, así como la observación del comportamiento de aceptación del macho. Las inseminaciones se realizaron cuando la citología vaginal tenía al menos el $90 \%$ de células superficiales, cada 48 horas hasta el cambio de citología vaginal a diestro y/o cuando la hembra dejaba de aceptar al macho. Para la recolección de semen se utilizó manipulación digital, los criadores fueron sometidos a un examen andrológico previo y se seleccionaron animales con una motilidad mínima del $70 \%$, vigor 3 y al menos 200x $10^{6}$ espermatozoides. La inseminación se realizó mediante la técnica intravaginal utilizando todo el eyaculado. El diagnóstico de gestación se realizó entre los días 25 y 30 de gestación, mediante un examen ecográfico, realizándose posteriormente de forma periódica para elegir el momento adecuado para la cesárea. El examen de citología vaginal, asociado con características anatómicas y de comportamiento, fue eficiente para detectar el estro en el 100\% de las hembras. De las 16 hembras inseminadas, 87,50\% (14/16) estaban preñas. Las camadas tuvieron una media de 5,6 crías, de las cuales el 53,16\% (42/79) fueron machos y el 46,84\% (37/79) hembras. La IA con semen fresco asociado con la citología vaginal proporcionó buenos resultados de fertilidad, así como camadas de tamaño compatible para la raza en cuestión.

Palabras clave: Biotecnología reproductiva, citología vaginal, gestación, canino

\section{Introdução}

A inseminação artificial (IA) é definida como sendo a deposição do sêmen no trato genital da fêmea, com auxílio de equipamentos específicos (Hafez \& Hafez, 2004). Na espécie canina, a IA com sêmen fresco teve sua demanda ampliada devido a maior procura dos criadores por assistência reprodutiva, por essa biotécnica apresentar resultados satisfatórios (Karling et al., 2018; Linde-Forsberg, 1991; Silva et al., 2001). Especificamente para a raça Buldogue, a justificativa para o uso da IA está no relato de proprietários que tiveram baixas taxas de prenhez e pequeno número de filhotes com monta natural, devido às dificuldades dos machos e fêmeas durante o acasalamento (Jacomini et al., 2006). Essa biotécnica pode ser utilizada como um meio alternativo quando não há aceitação do macho pela fêmea ou vice-versa, diferenças de tamanho e peso dos cães, quando um do casal possui algum tipo de dificuldade na monta natural por causa de problemas físicos e comportamentais, manejo do canil e diminuição de distâncias geográficas, uma vez que o sêmen resfriado e o congelado podem ser transportados possibilitando a manutenção da capacidade fecundante em animais de alto interesse 
zootécnico por um tempo prolongado, além de resguardar tais animais do estresse causado pelo seu transporte para fins de acasalamento (Guérin, 1998).

Para realização da IA é necessário que tanto o macho como a fêmea a serem utilizados estejam clinicamente sadios, não possuindo nenhum sinal clínico de doença infectocontagiosa e não sendo portador de anomalia genética e, que o cruzamento seja desejável em termos de padrão da raça em questão. Quando estes fatores forem satisfatórios, deverá ser realizado um exame andrológico no macho e ginecológico na fêmea para verificar se estão aptos dentro dos parâmetros adequados da esfera reprodutiva (Silva et al., 2001).

As principais vantagens dessa biotécnica da reprodução são a rápida disseminação do material genético de machos melhoradores, controle e prevenção de enfermidades, bem como diminuição de custos e estresse oriundos do transporte de animais (Silva et al., 2001).

Nesse sentido, o presente trabalho teve por objetivo a avaliação do proestro e estro por meio de citologia vaginal e a IA de cadelas da raça Buldogue Inglês com sêmen fresco, bem como a determinação da taxa de prenhez e o tamanho das ninhadas.

\section{Material e métodos}

Utilizaram-se 16 cadelas da raça Buldogue Inglês, com histórico de boa fertilidade reprodutiva e idade variando de 1,5 a 6 anos. Quando a fêmea apresentava alterações clínicas condizentes com proestro, como edema vulvar associado a secreção vaginal serosanguinolenta, atração do macho, mas não permitia ser acasalada, foi realizado um acompanhamento do ciclo estral por meio de citologia vaginal para a detecção do estro, no qual a vulva encontrava-se ainda edemaciada, com diminuição do corrimento vaginal e aceitação do macho, com exibição da vulva através da lateralização da cauda. A inseminação foi realizada quando a fêmea estava receptiva ao macho e apresentava uma citologia com pelo menos $90 \%$ de células epiteliais superficiais. Foram realizadas, em média, quatro exames de citologia vaginal por animal.

De um modo geral, utilizou-se para a IA, o macho de escolha do proprietário da cadela a ser inseminada. Contudo, a avaliação do reprodutor seguiu os seguintes passos: detalhada anamnese, verificando-se o desempenho reprodutivo anterior do macho e problemas de saúde prévios ou atuais, cuidadoso exame andrológico, incluindo a inspeção e palpação dos órgãos reprodutivos, observando-se principalmente o tamanho e a consistência testicular, visto que cães com espermatogênese anormal frequentemente têm testículos de consistência flácida, ao invés de fibroelástica. Em seguida, procedeuse à colheita e avaliação do sêmen e inspeção do comportamento de monta (Cunha, 2008).

Para a colheita do sêmen, empregou-se a massagem digital, sendo o ejaculado colhido em tubo plástico graduado acoplado a um funil plástico, pela maior facilidade de realização e por manter as características espermáticas semelhantes às obtidas na monta natural (Figura 1A). A avaliação da qualidade do sêmen canino incluiu a observação do volume, coloração, aspecto e odor, motilidade e vigor, além do cálculo da concentração e da morfologia espermática. Assim, só foi utilizado sêmen com uma motilidade mínima de $70 \%$, vigor mínimo de 3, pelo menos $200 \times 10^{6}$ de espermatozóides, defeitos maiores $<10 \%$ e menores $<20 \%$. Para a inseminação foi utilizado todo o ejaculado sem adição de meio diluente.

A IA intravaginal (IAIV), ou seja, deposição do sêmen no fundo de vagina da cadela foi empregada, pois é a via de escolha na maioria dos casos, por ser de fácil execução e por oferecer bons resultados. Para a IAIV foi utilizada uma sonda uretral número 8, conectada a uma seringa plástica de $10 \mathrm{~mL}$. A sonda foi introduzida na vagina no sentido dorso-cranial e todo o volume do ejaculado depositado. Após o procedimento, o posterior da cadela foi mantido elevado por cinco minutos, visando-se evitar o refluxo do sêmen (Figura 1B). As inseminações foram realizadas a cada 48 horas até mudança na citologia vaginal (diestro) e/ou quando a fêmea deixava de aceitar o macho. Foram realizadas, em média, três inseminações por animal.

O diagnóstico de gestação foi realizado entre os dias 25 a 30 de gestação, por meio de exame ultrassonográfico, sendo posteriormente feitos periodicamente para a escolha do momento apropriado 
para a cesariana. Quando havia falta de apetite da fêmea, liquefação do tampão mucoso e presença de motilidade intestinal fetal detectada por meio de ultrassonografia, a cesariana era realizada.
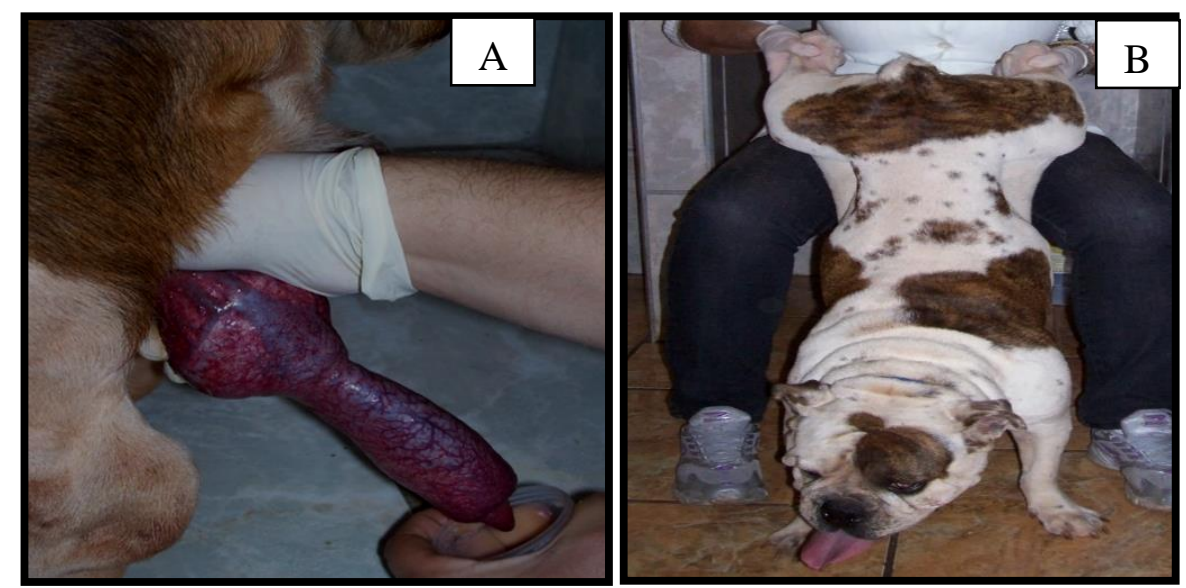

Figura 1. Fotografia (A) da colheita de sêmen, de um cão reprodutor, realizada por meio de manipulação digital; (B) de uma cadela da raça Buldogue Inglês com o posterior elevado após o procedimento de IA para evitar o refluxo de sêmen.

\section{Resultados e discussão}

O acompanhamento do ciclo estral com citologia vaginal foi realizado e apenas as fêmeas em estro (> 90\% de células superficiais) foram inseminadas. O exame da citologia vaginal, associado às características anatômicas e comportamentais, foi eficiente para detectar as cadelas em estro, conforme o descrito por Allen \& Maluenda (1993) e Johnston et al. (2001).

O diagnóstico de gestação realizado, por meio de exame ultrassonográfico foi eficiente para detectar 100\% das fêmeas prenhes durante o período supracitado, corroborando com Papp \& Fekete (2003). Todos os partos foram realizados por meio de cesariana. Nas fêmeas utilizadas nesta pesquisa, a necessidade de procedimento cirúrgico deveu-se, provavelmente, à anatomia peculiar da raça Buldogue Inglês e à conformação craniana dos fetos, que dificultaram a passagem dos filhotes pelo canal do parto (Jacomini et al., 2006; Linde-Forsberg, 2002).

Das 16 fêmeas inseminadas, 87,50\% (14/16) ficaram prenhas. Essa porcentagem foi semelhante ao descrito por Pinto et al. (1999) que obtiveram uma taxa de gestação de 94\%; porém, foi superior a relatada por Jacomini et al. (2006) e Tsutsui et al. (2003), que relataram taxa prenhez de $75 \%$ e $80 \%$, respectivamente. As ninhadas tiveram em média 5,66 $\pm 1,20$ filhotes, desses 53,16\% (42/79) eram machos e 46,84\% (37/79) fêmeas.

O tamanho da ninhada encontrado na literatura foi semelhante ao desse experimento, sendo em média de 6,17 \pm 2,66 filhotes, em cadelas da raça Buldogue Inglês submetidas a IA intravaginal, utilizando-se sêmen fresco (Jacomini et al., 2006). Esses dados demonstram que a IA intravaginal com sêmen fresco em cadelas da raça Buldogue Inglês é eficiente para promover a fecundação, garantindo taxa adequada de gestação e número de filhotes aceitáveis para a espécie.

\section{Considerações finais}

O processo de manipulação reprodutiva com o uso de IA associada à citologia vaginal mostrou ser eficiente, com boa taxa de gestação e bom número de filhotes, confirmando a viabilidade do uso desta biotécnica como rotina em programas de reprodução de canis especializados na raça Buldogue Inglês.

\section{Referências}

Allen, W. E., \& Maluenda, P. D. (1993). Fertility and obstetrics in the dog. Acribia.

Cunha, I. C. N. (2008). Exame andrológico do cão. Jornal Brasileiro de Ciência Animal, 1(1), 49-65. 
Guérin, C. (1998). A inseminação artificial na espécie canina. A Hora Veterinária, 105, 25-32.

Hafez, B., \& Hafez, E. S. E. (2004). Reprodução Animal (Vol. 1, p. 513). Manole: São Paulo, Brasil.

Jacomini, J. O., Cunha, G. N., Moreira, C. F., Diniz, E. G., \& Vieira, R. C. (2006). Uso da inseminação artificial como rotina em programas de reprodução de cadelas da raça Bulldog. Veterinária Notícias, 12(2), 141-144.

Johnston, S. D., Olson, M. V, Johnston, P. S. S. D., Kustritz, M. V. R., \& Olson, P. N. S. (2001). Canine and feline theriogenology. WB Saunders.

Karling, P. C., Roque, W. C., \& Olsson, D. C. (2018). Inseminação artificial a fresco em uma fêmea bulldog inglês: relato de caso. Revista de Ciência Veterinária E Saúde Pública, 4(2), 194-210. https://doi.org/10.4025/revcivet.v4i2.35671.

Linde-Forsberg, C. (2002). Pelvimetry to diagnose dystocia in the bitch. Proceedings of the 27th World Small Animal Veterinary Association World Congress, 591.

Linde-Forsberg, Catharina. (1991). Achieving canine pregnancy by using frozen or chilled extended semen. Veterinary Clinics of North America: Small Animal Practice, 21(3), 467-485. https://doi.org/10.1016/S0195-5616(91)50054-1.

Papp, Z., \& Fekete, T. (2003). The evolving role of ultrasound in obstetrics/gynecology practice. International Journal of Gynecology \& Obstetrics, 82(3), 339-346. https://doi.org/10.1016/S00207292(03)00224-8.

Pinto, C. R. F., Paccamonti, D. L., \& Eilts, B. E. (1999). Fertility in bitches artificially inseminated with extended, chilled semen. Theriogenology, 52(4), 609-616. https://doi.org/10.1016/S0093691X(99)00156-9.

Silva, L. D. M., Silva, A. R., \& Cardoso, R. C. S. (2001). Inseminação artificial em cães. In P. B. D. Gonsalves, J. R. F. Figueiredo, \& V. J. F. Freitas (Eds.), Biotécnicas Aplicadas à Reprodução Animal (pp. 69-95). Varella.

Tsutsui, T., Hori, T., Yamada, A., Kirihara, N., \& Kawakami, E. (2003). Intratubal insemination with fresh semen in dogs. Journal of Veterinary Medical Science, 65(5), 659-661. https://doi.org/10.1292/jvms.65.659.

\section{Histórico do artigo:}

Recebido: 4 de dezembro de 2020

Aprovado: 15 de janeiro de 2021.

Disponível online: 14 de abril de 2021.
Licenciamento: Este artigo é publicado na modalidade Acesso Aberto sob a licença Creative Commons Atribuição 4.0 (CC-BY 4.0), a qual permite uso irrestrito, distribuição, reprodução em qualquer meio, desde que $\mathrm{o}$ autor e a fonte sejam devidamente creditados 